\title{
Self-Control And Academic Performance In Engineering
}

Nora Honken, University of Cincinnati, USA

Patricia A Ralston, University of Louisville, USA

Thomas R. Tretter, University of Louisville, USA

\begin{abstract}
Self-control has been related to positive student outcomes including academic performance of college students. Because of the critical nature of the first semester academic performance for engineering students in terms of retention and persistence in pursuing an engineering degree, this study investigated the relationship between freshmen engineering students' scores on the Brief Self-Control Scale and first semester GPA. To identify the unique explanatory contribution of self-control beyond incoming academic performance differences, the effect of ACT Composite scores was statistically removed from the sample of three cohorts of freshmen engineering students $(n=1295$ total). The results showed the measure of self-control explained on average $4.2 \%$ of the residual variability in first semester GPA, after accounting for the variability explained by ACT scores. Based on results of this study, self-control predicted between 27\%-42\% as much of the variance in first semester GPA as did ACT scores, a much-used high stakes measure frequently used for decisions such as program admittance or mathematics course placement. Thus self-control is a nontrivial predictor of academic performance. Based on post hoc analysis, relevant self-control behaviors might manifest themselves in time and study management since there was a significant correlation between self-control scores and scores on the MSLQ time and study management measure. These results have implications for both how much of an impact positive self-control may have on freshmen engineering academic performance, while also offering potential avenues to support students in bolstering aspects of this personality trait through a focus on strengthening time and study management skills.
\end{abstract}

Keywords: Self-Control; ACT Scores; First Year Engineering; First Year Academic Performance

\section{INTRODUCTION}

ood self-control has been related to many positive outcomes related to health, success, wellbeing, and crime avoidance (Baumeister \& Vohs, 2004; De Ridder, Lensvel-Mulders, Finkenauer, Stock, \& Baumeister, 2012; Duckworth, Quinn, \& Tsukayama, 2012; Duckworth \& Seligman, 2005; Goldfried \& Merbaum, 1973; Moffitt et al., 2011; Tangney, Baumeister, \& Boone, 2004; Zettler, 2011). Policy-makers have considered large-scale programs aimed at improving self-control with the hope of improving the health and wealth of the citizenry and reducing crime (Moffitt et al., 2011). Important to the current study is the link between self-control and academic performance.

The trait of self-control is found in a plethora of research studies, predominately in the field of psychology. Although self-control is considered an important trait, no single accepted definition or name is used consistently. Self-control has been referred to as self-regulation, self-discipline, and willpower, among other names (Duckworth \& Kern, 2011). Duckworth, Quin and Tsukayama (2012) acknowledge the confusion between the meaning of selfcontrol and self-regulation and differentiate them as "self-control" being a personality trait that voluntarily regulates impulses to meet long-term goals and "self-regulation" being metacognitive strategies that help in meeting personal goals. Similar attempts to distinguish between the two are described in Kuhl and Fuhrmann (1998), McCullough and Willoughby (2009), and Carver and Scheier (1998). Storch (2005) succinctly sets self-control and selfregulation apart by saying "self-control helps you meet small challenges, but to change your life significantly you'll need self-regulation" (p. 88). 
Some authors, such as Roy Baumeister who has written extensively on self-control, have changed their views on self-control over time. In 1994, Baumeister, Heatherton and Tice (1994) viewed self-control and self-discipline as conceptions of self-regulation. They formulated four domains of self-control as controlling thoughts, emotions, impulses, and performance. They used self-regulation in a broader sense to refer to overriding a natural response in favor of another response. In 2004, Baumeister and Vohs (2004) used self-control and self-regulation interchangeably and defined it as "any efforts by the human self to alter any of its own inner states or responses" (p. 2).

With this background in mind, this study used the definition of self-control from the creators of the Brief SelfControl Scale (Tangney et al., 2004). Central to their definition of self-control is the "ability to override or change one's inner responses, as well as to interrupt undesired behavioral tendencies (such as impulses) and refrain from acting on them" ( p. 274). They believe self-control encompasses four domains: controlling thoughts, emotions, impulse, and performance; thus these are measured in Brief Self-control Scale used in the current study. Their research in self-control focused on the following domains: achievement and task performance (school and work), impulse control, psychological adjustment (symptoms of anxiety, depression, and obsessive-compulsive behavior), interpersonal relationships, and moral emotions (shame and guilt).

\section{FRAMEWORK AND SUPPORTIVE LITERATURE}

This study was framed in past research on self-control and academic performance. The review of this literature is separated by the population researched: K-12 students, general postsecondary students and engineering students.

\section{Research with K-12 Students}

The relationship between self-control and academic performance has been investigated with students at the middle school level, which is a time of transition and a point when students typically start to become more aware of the contribution of effort and intelligence (Duckworth et al., 2012). In a study of two consecutive $8^{\text {th }}$ grade cohorts from a public magnet school, Duckworth and Seligman (2005) found a significant relationship $(p<.001)$ between what they called self-discipline and first marking period grades $(r=.52$ cohort 1 and $r=.66$ cohort 2$)$ and final grades $(\mathrm{r}=$ .55 and $r=.67)$ in both groups of students. Hofer, Kuhnle, Kilian, \& Fries (2012) studied a group of eighth graders (48\% male, $52 \%$ female) who were from 10 different schools with different levels of challenging curriculum and found that self-control and procrastination explained four times more variance in grades than did cognitive ability, but that cognitive ability was more strongly correlated with standardized test scores.

Duckworth et al. (2012) led a study of middle school students and concluded that self-control measures were better predictors of grades, but IQ was a stronger predictor of standardized achievement test scores. They suggest that "intelligence helps students learn and solve problems independent of formal instruction, whereas self-control helps students study, complete homework and behave positively in the classroom" (p. 439). More recently, Galla, et al. (2014) designed an "academic diligence task", a behavioral measure of self-control that tested 921 high school seniors' ability to resist digital distractions. Impressively, their results showed performance on the test (ability to stay on task and avoid the digital distractions) demonstrated incremental predictive validity for objectively measured GPA, standardized math and reading achievement test scores, high school graduation, and college enrollment, over and beyond demographics and intelligence.

\section{Research with College Students}

The relationship between self-control and academic performance has also been studied at the college level, another time of transition. In a multiple regression study ( $n=201,78 \%$ females, $22 \%$ males) to predict college GPA in psychology students, Wolfe and Johnson (1995) considered high school GPA, SAT scores, and 32 personality traits. After accounting for high school GPA, self-control accounted for the most variability in college GPA (9\%); SAT total score was next $(5 \%)$.

Tangney, Baumeister and Boone (2004) conducted two studies investigating the relationship between self-control and multiple factors including college grades. The participants in their studies were undergraduates in a psychology 
course with a preponderance of females in the first study ( $n=351,72 \%$ females, $28 \%$ male) and an even higher percentage of females in the second study $(n=255)$. Analysis in both studies showed a significant positive relationship between GPA and self-control. Thus, on average, the students with higher reported self-control had higher grades. The authors attributed this phenomenon to students with higher self-control being better at "getting tasks done on time, preventing leisure activities from interfering with work, using study time effectively, choosing appropriate courses and keeping emotional distractions from impairing performance" (p. 275).

\section{Research with Engineering Students}

Previously the authors of this study (Honken \& Ralston, 2013) investigated the relationship between lack of selfcontrol and academic performance in first year engineering students. Based on the rigors of the engineering curriculum (National Society of Student Engagement, 2011) and the difference in engineering students when compared to students in other majors, particularly the reported hours needed for study (National Center for Science and Engineering Statitistics, 2012; Zhang, Carter, Thorndyke, Anderson, \& Ohland, 2003) and the perdomance of males, it is worthwhile to investigate engineering students separate from the general population of college students.

The study involved 321 first-time, full-time engineering students (16\% female, $84 \%$ male), they found a significant negative relationship, after statistically controlling for the predictive power of incoming ACT, between first semester GPA and the frequency a student reported engaging in actions that showed lack of self-control in high school. The measure of lack of self-control was the students' self-reported frequency of illegal or irresponsible behavior taken from the Cooperative Institutional Research Program (CIRP) Freshman Survey. No significant relationship between ACT scores and self-control was found in the study. While irresponsible behaviors such as underage drinking appear to indicate a lack of self-control, one cannot assume they necessarily would be related to lack of self-control as measured by a validated scale. Thus the current study built on these past studies and filled an apparent gap in the literature by investigating self-control in engineering students using an established instrument, the Brief Self-Control Scale (Tangney et al., 2004), to measure self-control. Replication of our initial results using a widely accepted and easily implemented instrument will make a compelling case for the importance of developing self-control.

\section{PURPOSE, RESEARCH QUESTIONS AND SIGNIFICANCE OF THIS STUDY}

The purpose of the current study was to better understand the relationship between self-control, academic ability and first semester GPA for freshman engineering students, with the goal of helping to determine ways to potentially improve academic performance of freshmen engineering students. First year engineering performance is due to many interrelated factors that are often difficult to characterize. It is well accepted that a major contributing factor is academic ability. If self-control, a trait that isn't static and can be developed by students, were shown to have a significant relationship with first year academic performance, it could be communicated readily to students, parents, and faculty, potentially improving future students' success in engineering programs. Early academic performance of engineering students is of key importance for retention. Poor academic performance has been cited by students as a major reason for leaving engineering (Seymour \& Hewitt, 1997) and studies have found a significant difference in average GPA between students who leave engineering and those who continue to study engineering (French, Immekus, \& Oakes, 2005; Moses et al., 2011; Veenstra, Dey, \& Herrin, 2009). Further, many scholarships require students to maintain a certain GPA (Mobley, Brawner, \& Ohland, 2009; Zhang, Min, Frillman, Anderson, \& Ohland, 2006). It is unknown what percentage of engineering students nationwide have a scholarship, but results of the 2011 Cooperative Institutional Research Institute (CIRP) Freshman Survey showed 27\% of all college freshman who completed the survey specified they had scholarships totaling over $\$ 10,000$, and $70 \%$ of the freshmen had some form of grant or scholarship (Pryor, Deangelo, Blake, Hutado, \& Tran, 2011). Another goal of the study was to help high school students more easily understand factors related to academic success in first year engineering studies, thus helping them make a more informed decision as they choose to pursue an engineering degree.

The research question was: Is there a significant amount of variability in first semester GPA for engineering students at a large metropolitan research institute that can be explained by scores on a self-control scale, after accounting for the variability explained by ACT Composite scores? Based on the reported literature it was hypothesized that selfcontrol scores will consistently explain some of the variability in first semester GPA. 


\section{Participants}

\section{RESEARCH METHODS}

The participants in this study were all first-time, full-time engineering students in the 2012, 2013 and 2014 cohorts at one large metropolitan research institution. Students were excluded if they did not take the survey, did not complete all 13 questions on the Brief Self-Control Scale or if they had not submitted ACT or SAT scores. Of the 430 students officially in the 2012 cohort, data from 394 (91\%) were used in the analysis. Of 505 students in the 2013 cohort, data from 451 (89\%) students were analyzed. And of the 489 students in the 2014 cohort 450 (92\%) were used in the analysis, resulting in an overall sample size of 1295 (91\% of the combined enrollment). Table 1 shows the ethnic and gender data for the 2012 cohort, which is typical of the university and representative for all three cohorts.

Table 1. 2012 Ethnic and Gender Distribution of Participants

\begin{tabular}{|c|c|}
\hline & Included in analysis \\
\hline Females & $\begin{array}{c}90 \\
(22 \%)\end{array}$ \\
\hline Males & $\begin{array}{c}325 \\
(78 \%)\end{array}$ \\
\hline Caucasians & $\begin{array}{c}345 \\
(85 \%)\end{array}$ \\
\hline Asians & $\begin{array}{c}17 \\
(4 \%)\end{array}$ \\
\hline Hispanic/Latino & $\begin{array}{c}16 \\
(4 \%)\end{array}$ \\
\hline African American & $\begin{array}{c}13 \\
(3 \%)\end{array}$ \\
\hline Two or more races & $\begin{array}{c}12 \\
(3 \%)\end{array}$ \\
\hline Nonresident Alien & $\begin{array}{c}2 \\
(<1 \%)\end{array}$ \\
\hline Other & $\begin{array}{c}1 \\
(<1 \%)\end{array}$ \\
\hline
\end{tabular}

The National Center of Education Statistics (NCES) requires missing data analysis on studies with response rates lower than $85 \%$ (Chen, 2013). Since the participation rate for all three cohorts was over $85 \%$, no missing data analysis was performed.

\section{Instruments}

\section{Self-control}

Multiple instruments have been developed to measure self-control such as the Self-Control Behavior Inventory (Fagen, Long, \& Stevens, 1975); Self-Control Questionnaire (Brandon, Oesher, \& Loftin, 1990); Barratt Inclusiveness Scale (Patton, Stanford, \& Barratt, 1995); Self-Control Schedule (Rosenbaum, 1908); Low-SelfControl Scale (Grasmick, Tittle, Bursik, \& Arneklev, 1993); the Self-Control Scale (Tangney et al., 2004); and the subscale of the California Personality Inventory (Gough, 1987). The measurements are specific to the developers' understanding of self-control in the context in which they were working. The Brief Self-Control Scale, a 13 item subset of the 36 item Self-Control Scale (Tangney et al., 2004) was chosen for this study because of its wide spread use and appropriateness for use with academic outcomes (De Ridder et al., 2012). Over 50 studies have used the Self-Control Scale or some variant of it. The Self-Control Scale (Tangney et al., 2004) was built around the following concept, which captures the nature of self-control necessary for the extensive and focused studying efforts typically needed in engineering courses:

Regulating the stream of thought (e.g., forcing oneself to concentrate, altering moods or emotions) restraining undesirable impulses, and achieving optimal performance (e.g., making oneself persist) all 
constitute important instances of the self-overriding its responses and altering its states or behavior. More generally, breaking bad habits, resisting temptation, and keeping good self-discipline all reflect the ability of the self to control itself, and we sought to build our scale around them. (Tangney et al., 2004, p. 275)

The scale was introduced on the surveys with the following question: "With respect to school, how frequently does each of the following statements apply to you?" The entire scale is in the appendix, a sample item reads "I do certain things that are bad for me, if they are fun." The available responses were (1) Never, (2) Seldom, (3) Sometimes, (4) Often, and (5) Always. The self-control score was calculated by adding all items on the scale after appropriate responses were reversed.

Creators of the scale reported Cronbach alphas of .83 and .85 in two different studies and test retest reliability of .87 $(n=233)$, however no results of convergent validity of each of the individual items converging on one common construct were reported (Tangney et al., 2004). Using the data from this current study, the scale had good internal consistency reliability (Cronbach alpha $=.84$ ). To check for convergent validity of each of the scale's individual items loading onto one common construct, data were analyzed using confirmatory factor analysis (see appendix for results). Based on the criteria cited by Kline (2011) that factor loadings less than .7 might signal an issue with convergent validity, there is some concern about the convergent validity of this scale. However, most of the factor loadings ( 8 out of 13 ) were at least 0.55 or higher, and none were extremely low ( 0.38 was the lowest). This is understandable in light of the complex nature of self-control. The Brief Self Control Scale developers state that it measures multiple features that collectively comprise self-control as an overall construct. However, these multiple features are distinct from each other, which likely contributes to weakening the factor loadings of individual items to the overall construct of "self-control." Thus, while there may be some convergent validity issues with the selfcontrol measure, nevertheless it is commonly used to advance the state of knowledge in this field (De Ridder, 2012).

$A C T$

According to ACT the test is designed to predict academic achievement in the first year of college (ACT, nd). It is viewed as a measure of college readiness and used as a predictor of future academic success. The composite score is made up of the average of scores on four separate tests: Math, Science, English and Reading. The scores on each individual test and the composite score range from 1 to 36 .

\section{Motivated Strategies for Learning Questionnaire (MSLQ)}

As part of a larger data collection strategy to uncover how to best support the academic success of first-year engineering students, students in the 2012 cohort were administered the Motivated Strategies for Learning Questionnaire (MSLQ) (Pintrich, et al, 1991) midway through the first semester in week eight. After computing the predictive power of self-control in predicting first-semester GPA as reported in results section below, results from the MSLQ were used in a post-hoc analysis to identify potential learning strategies that might be helpful to target in supporting students. The MSLQ included 6 categories of learning strategies (see Table 5 in results section).

\section{Data Collection}

As part of a larger study to help improve first year retention, the Brief Self-Control survey was administered to firsttime, full-time students enrolled in a required course for freshman engineering students. Each year the survey was emailed to students during the first week of the fall semester by employees in the Office of Institutional Effectiveness, a department within Institutional Research. Students were given class time to complete the survey, but no rewards or class credit were given. ACT scores and first semester GPAs were extracted from student records and connected to each student's survey results. After student IDs were replaced with research IDs by Institutional Effectiveness personnel to insure student anonymity to the research team, the data were released to the researchers.

\section{Data Analysis}

The data from each cohort were analyzed using regression analysis in SPSS rev. 22. Stepwise entry was used and $\mathrm{R}^{2}$ was calculated for each step of the model. 


\section{RESULTS}

The descriptive statistics for the variables are shown in Table 2. The possible values for each variable are: ACT Composite score (1-36), self-control score (13-65) and first semester GPA $(0-4.0)$. There was a significant correlation between GPA and ACT composite score and between GPA and self-control score for all the cohorts (see Table 3). As in our previous study (Honken \& Ralston, 2013), the correlation between ACT composite score and the self-control score were not significant in any of the cohorts.

Table 2. Descriptive Statistics for Variables in the Analysis

\begin{tabular}{l|c|c|c|c}
\hline Cohort & Min & Max & Average & Standard deviation \\
\hline 2012 & & & & 28.4 \\
\hline ACT Composite & 22 & 35 & 46.9 & 3.14 \\
\hline Self-control score & 28 & 64 & 2.86 & 6.53 \\
\hline GPA & .65 & 4.00 & & .79 \\
\hline 2013 & & & 28.6 & 3.13 \\
\hline ACT Composite & 22 & 36 & 45.9 & 7.03 \\
\hline Self-control score & 27 & 65 & 2.91 & .76 \\
\hline GPA & .50 & 4.00 & & \\
\hline 2014 & & & 28.9 & \\
\hline ACT Composite & 23 & 35 & 48.0 & 2.94 \\
\hline Self-control score & 24 & 65 & 2.86 & 7.04 \\
\hline GPA & 0 & 4.00 & & .95 \\
\hline
\end{tabular}

Table 3. Correlations for All Three Cohort

\begin{tabular}{l|c|c|c}
\hline & $\mathbf{2 0 1 2}$ & $\mathbf{2 0 1 3}$ & $\mathbf{2 0 1 4}$ \\
\hline ACT composite / GPA & $.464 *$ & $.357 *$ & $.299 *$ \\
\hline Self-control / GPA & $.237 *$ & $.213 *$ & $.186 *$ \\
\hline ACT composite / Self-control & -.004 & -.055 & -.005 \\
\hline
\end{tabular}

* Significant at $\mathrm{p}<.01$

Table 4 contains the $\mathrm{R}^{2}$ values for each of the cohorts. For all cohorts ACT composite score was the first variable to be added to the model. The amount of variability in GPA explained by ACT composite scores varied from a high of $18.4 \%$ in 2012 to a low of $8.5 \%$ in 2014 . The amount of variability explained by the self-control score was more consistent and averaged $4.2 \%$, with $\mathrm{R}^{2}$ ranging from.035 to .052 . Based on a premise that ACT scores are intended to be predictors of academic success in the first year, many institutions attach substantial consequences to incoming ACT scores such as acceptance into a program or placement in a first mathematics course. Thus, in order to estimate the effect size of the predictive power of self-control on first semester academic performance, one useful benchmark is to compare the percentage of variability explained $\left(\mathrm{R}^{2}\right)$ by self-control to that explained by ACT scores. In the current study, the self-control $\mathrm{R}^{2}$ compared to ACT $\mathrm{R}^{2}$ ranged from $.049 / .184=.27$ in the 2012 cohort to $.052 / .124=.42$ in the 2013 cohort (see Table 4). So while the self-control measure doesn't capture as much variance in first semester academic performance as the much-used ACT for high stakes decisions, our results showed that self-control could predict between $27 \%-42 \%$ as much of the variance in first semester academic performance as ACT, which is a nontrivial contribution.

Table 4. $\mathrm{R}^{2}$ Different Models

\begin{tabular}{l|c|c|c|c}
\hline Cohort & $\mathbf{R}^{\mathbf{2}}$ just ACT & $\begin{array}{c}\mathbf{R}^{\mathbf{2}} \text { ACT and } \\
\text { Self-control }\end{array}$ & $\begin{array}{c}\text { Change in } \mathbf{R}^{\mathbf{2}} \\
\text { when self-control added }\end{array}$ & $\begin{array}{c}\text { Ratio of } \mathbf{R}^{\mathbf{2}} \text { of self-control } \\
\text { compared to ACT }\end{array}$ \\
\hline 2012 & .184 & .233 & .049 & .27 \\
\hline 2013 & .124 & .176 & .052 & .42 \\
\hline 2014 & .085 & .120 & .035 & .41 \\
\hline
\end{tabular}




\section{Post Hoc Analysis}

Since the data for this study were taken from a larger survey, we were able to correlate self-control scores to other measures to determine how self-control might manifest itself. Table 5 shows the correlation between the scores on the Brief Self-control Scale and sub scales on the Motivated Strategies for Learning Questionnaire (MSLQ) (Pintrich, 1991). The strongest correlation was with time study environment management.

Table 5. Correlation between Self-control Score and Items on the MSLQ ( $n=356)$

\begin{tabular}{l|cc}
\hline & Pearson Correlation & Sig. (2-tailed) \\
\hline Time study environment management & .330 & $<.001$ \\
\hline Metacognitive self-regulation & .295 & $<.001$ \\
\hline Test anxiety & -.173 & .001 \\
\hline Internal goal orientation & .130 & .014 \\
\hline Elaboration & .110 & .038 \\
\hline Critical thinking & .041 & .442 \\
\hline
\end{tabular}

In previous studies the score on the category "time study environmental management" has had the high correlation with GPA (Pintrich, 1991). Although not conclusive, these results suggest that the variability in GPA that is related to self-control predominantly manifests itself in time and study environment skills.

\section{DISCUSSION}

Although the results of the study confirmed the results of multiple studies discussed earlier in this paper, as with all studies, the results must be interpreted within the limitations of the study. Most studies investigating self-control used students' self-reported self-control scores, as did the current study. It is unknown how accurately the students' scores reflect their actual behavior. As mentioned previously, the internal consistency reliability of the Brief SelfControl Scale was good, but confirmatory factor analysis indicated there might be an issue with convergent validity. The scale has been used in multiple studies, but has received some criticism for potential problems with unidimensionality and validity (Maloney, Grawitch, \& Barber, 2012). Finally, the sample in this study does not reflect the national population of engineering students as it was less ethnically diverse.

In the current study, the percentage of variability in grades explained by self-control scores averaged $4.2 \%$ and was relatively consistent across the three cohorts. In comparison to the explanatory power of the ACT in predicting first semester GPA, we found that self-control explains between $27 \%-42 \%$ as much of the variability as incoming ACT scores did. Thus, while self-control may not be as powerful as ACT as an indicator of future academic success for entering engineering students, it nevertheless contributes substantially as a meaningful predictor. The results add to mounting evidence that self-control contributes to academic performance for engineering students as well as other college students studied in previous work. Thus, self-control as operationalized in this study is a trait that individuals should acquire, if not before college, while they are in college. Unlike incoming ACT scores, higher education schools of engineering may have an opportunity to influence self-control behaviors, and hence positively influence academic success of their incoming freshmen.

There is evidence that self-control can be improved (Duckworth \& Seligman, 2005; Elstad, 2008; Muraven, Baumeister, \& Tice, 1999). Duckworth and Seligman (2005) promote programs that build self-discipline as the "royal road to building academic achievement" (p. 944). Elstad (2008) recommends schools design instructional arrangements to scaffold students in the use of self-discipline strategies. Moffitt and colleagues (2011) recommend self-control training in early childhood and then again in adolescence, based on the belief that the longer you wait to improve self-control the harder it is to change. However, despite the fact that the incoming level of self-control within a freshmen cohort is outside the control of the university, engineering programs can support and influence the learning of good self-control behaviors for incoming students. For example, they might provide more peer mentoring or give guidance in environmental, behavioral or cognitive strategies that might improve self-control.

Since in post hoc analysis, self-control scores were significantly correlated with time study environment management scores, which have been shown to be related to GPA, one avenue of helping students with low self- 
control is to help them with their time study environment management skills. Many schools already offer sessions in time management and it would be easy for students who were identified as having low self-control to be strongly encouraged to take advantage of this service. These endeavors could potentially improve the likelihood of better academic achievement during the first semester and beyond. Answering these questions could lead to effective ways to assist all students, not only those in engineering, who enter college with low self-control.

\section{CONCLUSION AND FUTURE RESEARCH}

This study prompts multiple new research questions. Is the variability in GPA explained by self-control different in engineering from other disciplines? Answering this question might help students when making college major decision. Can structured/required study times help students with low self-control? Can study areas created to eliminate distractions, such as, no Wi-Fi areas help students with low self-control? Does making students aware of their self-control level encourage them to improve their time study environment management or attend a time management course?

Baumiester, Heatheron and Tice (1994) believe that the majority of the personal and social problems in Western societies can be related to lack of self-control. Moffitt and colleagues (2011) showed poor self-control as a child (3 to 11 years old) explained almost as much variability in adult health, finances and crime as did social class or IQ. Duckworth and Seligman (2005) speculate that lack of self-discipline and focus on short term goals is a major cause of students not reaching their intellectual potential. Some are concerned that due to the increased distractions created by technology such as smart phones, that the need to develop self-control is now even more important to academic success (Elstad, 2008). Whatever the potential causes of lack of self-control, this study contributes to evidence that self-control is important for success for first year engineering students. Unlike ACT scores, selfcontrol scores are not readily available as a selection criterion for acceptance into engineering. None-the-less, the importance of self-control should be part of the dialog with students considering studying engineering, and potentially other majors as well. If the trend, observed in this study, of ACT scores explaining less of the variability in GPA is accurate, more measures will be needed to help students understand their potential for success in an academic program.

\section{AUTHOR BIOGRAPHEIS}

Nora Honken is an Assistant Professor - Educator in the Department of Engineering. She teaches freshman engineering courses and focuses her research on engineering student performance and retention. Dr. Honken holds degrees in industrial engineering and educational leadership. She has extensive industrial experience in engineering and management. E-mail: honkenna@uc.edu

Patricia A. S. Ralston is Professor and Chair of the Department of Engineering Fundamentals. Dr. Ralston teaches undergraduate engineering mathematics and performs educational research on the effective use of technology in engineering education, the incorporation of critical thinking in undergraduate engineering education, and retention of engineering students. She leads a research group whose goal is to foster active interdisciplinary research which investigates learning and motivation to promote retention and student success in engineering. Her fields of technical expertise include process modeling, simulation, and control. E-mail: parals01@louisville.edu

Thomas Tretter is Professor of Science Education, Director of the Center for Research on Mathematics and Science Teacher Development, and Director of the University's Gheens Science Hall \& Rauch Planetarium. Dr. Tretter teaches beginning and experienced science teachers, doctoral students in science education, and ongoing workshops and professional development for practicing K-12 teachers. His research includes explorations of efficacy of visually rich media for supporting student learning of science, and research into undergraduate science and engineering student learning as well as university faculty support structures. E-mail: tom.tretter@louisville.edu 


\section{REFERENCES}

ACT (nd). What is the differnece between the Act and the SAT? ACT accessed January 20, 2016 from http://www.actstudent.org/faq/actsat.html.

Baumeister, R. F., \& Vohs, K. D. (2004). Handbook of self-regulation: Research, theory and applications. New York: The Guilford Press.

Baumeister, R. F., Heatherton, T. E., \& Tice, D. M. (1994). Losing control: How and why people fail at self-regulation. San Diego, CA: Academic Press, Inc.

Brandon, J. F., Oesher, J., \& Loftin, J. M. (1990). Self-control behavior inventory. Health Values, 14, 3-19.

Carver, C. S., \& Scheier, M. F. (1998). On self-regulation of behavior. New York, NY: Cambridge University Press.

Chen, X. (2013). STEM attrition: College students paths into and out of stem fields (NCES 2014-01). Washington, DC: National Center for Education Statistics, Institute of Education Sciences.

De Ridder, D. T., Lensvel-Mulders, G., Finkenauer, F., Stock, F. M., \& Baumeister, R. F. (2012). Taking stock of self-control: A meta-analysis of how trait self-control relates to a wide range of behaviors. Personality and Social Psychology Review, 16(1), 76-99.

Duckworth, A. L., \& Kern, M. L. (2011). A meta-analysis of the convergent validity of self-control measures. Journal of Research in Personality, 45(3), 259-268. doi: 10.1016/j.jrp.2011.02.004

Duckworth, A. L., Quinn, P. D., \& Tsukayama, E. (2012). What No Child Left Behind Leaves Behind: The role of IQ and selfcontrol in predicting standardized achievement test scores and report card grades. Journal of Educational Psychology, 104(2), 439-451.

Duckworth, A. L., \& Seligman, M. E. P. (2005). Self-discipline outdoes IQ in predicting academic performance of adolescents. Psychological Science (Wiley-Blackwell), 16(12), 939-944. doi: 10.1111/j.1467-9280.2005.01641.x

Duckworth, A. L., \& Seligman, M. E. P. (2006). Self-discipline gives girls the edge: Gender in self-discipline, grades and achievement test scores. Journal of Educational Psychology, 98(1), 198-208. doi: 10.1037/0022-0663.98.1.198

Elstad, E. (2008). Building self-discipline to promote learning: Students' volitional strategies to navigate the demands of schooling. Learning Inquiry, 2(1), 53-71.

Fagen, S. A., Long, W. J., \& Stevens, O. J. (1975). Teaching children self-control: Preventing emotional and learning problems in the elementary school. Columbus, OH: Charles E. Merrill.

French, B. F., Immekus, J. C., \& Oakes, W. C. (2005). An examination of indicators of engineering students' sucess and persistence. Journal of Engineering Education, 94, 419-425.

Galla, B.M., Plummer, B.D., White, R.E., Meketon, D., D’Mello, S.K., \& Duckworth, A.L. (2014). The Academic Diligence Task (ADT): Assessing individual differences in effort on tedious but important schoolwork. Contemporary Educational Psychology,39(4), 314-325.

Goldfried, M. R., \& Merbaum, M. (1973). A perspective on self-control. Behavior change through self-control, 3-34.

Gough, H. G. (1987). California Personality Inventory-administration guide. Palo Alto, CA: Consulting Psychologists Press.

Grasmick, H. G., Tittle, C. R., Bursik, R. J. J., \& Arneklev, B. J. (1993). Testing the core empirical implications of Gottfredson and Hirschi's General Theory of Crime. Journal of Research in Crime and Delinquency, 30, 5-29.

Hofer, M., Kuhnle, C., Kilian, B., \& Fries, S. (2012). Cognitive ability and personality variables as predictors of school grades and test scores in adolescents. Learning and Instruction, 22, 368-375.

Honken, N.B., and Ralston, P.A.S. (2013). High achieving high school students and not so high achieving college students: A look at self control, academic ability, and performance in college. Journal of Advanced Academics, 24 (2), 108-124.

Kuhl, J., \& Fuhrmann, A. (1998). Decomposing self-regulation and self-control: The Volitional Components Inventory. U.S.A.: Cambridge University Press.

Maloney, P. W., Grawitch, M. J., \& Barber, L. K. (2012). The multi-factor structure of the Brief Self-control Scale: Discriminant validity of restraint and impulsivity. Journal of Research in Personality, 46(1), 111-115. doi: 10.1016/j.jrp.2011.10.001

McCullough, M. E., \& Willoughby, B. L. (2009). Religion, self-regulation, and self-control: Associations, explanations and implications. Psychological Bulletin, 135(1), 69-91.

Mobley, C., Brawner, C., \& Ohland, W. (2009). The South Carolina Merit Scholarship; Strategies used by engineering students to keep their Life Scholarship. International Journal of Engineering Education, 25(6), 1249-1256.

Moffitt, T. E., Arseneault, L., Belsky, D., Dickson, N., Hancox, R. J., Harrington, H., Caspi, A. (2011). A gradient of childhood self-control predicts health, wealth, and public safety. Proceedings of the National Academy of Sciences of the United States of America, 108(7), 2693-2698. doi: 10.1073/pnas.1010076108

Moses, L., Hall, C., Wuensch, K., DeUrquidi, K., Kauffman, P., Swart, W., \& Dixon, G. (2011). Are math readiness and personality predictive of first-year retention in engineering? The Journal of Psychology, 145(3), 229-245.

Muraven, M., Baumeister, R. F., \& Tice, D. M. (1999). Longitudinal improvement of self-regulation through practice: Building self-control strength through repeated exercise. The Journal of social psychology, 139(4), 446-457.

National Center for Science and Engineering Statistics. (2012). Science and engineering indicators 2012. Retrieved May 6, 2013, from http://www.nsf.gov/statistics/seind12/c2/c2s2.htm\#s2 
National Science Foundation. (2013). Women, minorities and persons with disabilities in science and engineering (table 2-9 undergraduate enrollment in engineering programs by sex, race/ethnicity, citizenship and enrollment status: 19992009). In National Science Foundation (Ed.). Arlington, VA.

National Society of Student Engagement. (2011). Fostering student engagement campuswide-annual results 2011. Bloomington, IN: Indiana University Center for Postsecondary Research.

Patton, J. H., Stanford, M. S., \& Barratt, E. S. (1995). Factor structure of the Barrett Impulsiveness Scale. Journal of Clinical Psychology, 51, 768-774.

Pintrich, P., Smith, D., Garcia, T. \& McKeachie (1991). A manual for the use of the Motivated Strategies for Learning Questionaire (MSLQ). Office of Education Research and Improvement (NCRIPTAL-91-B-004). Washington DC.

Pryor, J. H., DeAngelo, L., Blake, L. P., Hutado, S., \& Tran, S. (2011). The American freshman national norms fall 2011. Los Angeles: Higher Education Research Institution, UCLA.

Rosenbaum, M. (1908). A schedule for assessing self-control behaviors preliminary findings. Behavior Therapy, 11, $109-121$.

Seymour, E., \& Hewitt, N. M. (1997). Talking about leaving: Why undergraduates leave the sciences. U.S.A.: Westview Press.

Storch, M. (2005). Taking the reins. Scientific American Mind, 16(2), 88.

Tangney, J. P., Baumeister, R. F., \& Boone, A. L. (2004). High self-control predicts good adjustment, less pathology, better grades and interpersonal success. Journal of Personality, 72(2), 271-322.

Veenstra, C. P., Dey, E. L., \& Herrin, G. D. (2009). A model for freshman engineering retention. In A. S. o. E. Education (Ed.), Advances in Engineering Education (Vol. Winter 2009).

Wolfe, R. N., \& Johnson, S. D. (1995). Personality as a predictor of college performance. Educational \& Psychological Measurement, 55(2), 177 - 186.

Zettler, I. (2011). Self-control and academic performance: Two field studies on university citizenship behavior and counterproductive academic behavior. Learning and Individual Differences, 21(1), 119-123. doi: 10.1016/j.lindif.2010.11.002

Zhang, G., Carter, R., Thorndyke, B., Anderson, T. J., \& Ohland, M. W. (2003). A comparison of demographic factors and academic performance between students graduated in engineering and other disciplines. Paper presented at the American Society of Engineering Education Southeast Division, Nashville, TN.

Zhang, G., Min, Y., Frillman, S. A., Anderson, T. J., \& Ohland, M. W. (2006). Students strategies for protecting merit-based scholarships: Grades, courseload, and major choice. Paper presented at the 36th ASEE/IEEE Frontiers in Education Conference, San Diego, CA. 


\section{APPENDIX}

Table 6 Items on the Brief Self-Control Scale and Factor Loadings from Confirmatory Factor Analysis with Responses on the Week 1 Survey $(n=415)$

\begin{tabular}{l|c}
\multicolumn{1}{c}{ Brief Self-Control Scale Item } & Standardized regression estimate \\
\hline I do certain things that are bad for me, if they are fun. ${ }^{*}$ & 0.404 \\
\hline I have a hard time breaking bad habits. & 0.546 \\
\hline I am lazy. & 0.645 \\
\hline I act without thinking through all the alternatives. ${ }^{*}$ & 0.478 \\
\hline I am good at resisting temptation. & 0.561 \\
\hline I refuse things that are bad for me. & 0.451 \\
\hline I am able to work effectively towards long-term goals. & 0.586 \\
\hline People would say that I have iron self-discipline. & 0.631 \\
\hline Pleasure and fun keep me from getting work done. & 0.569 \\
\hline I have trouble concentrating. ${ }^{*}$ & 0.481 \\
\hline I wish I had more self-discipline. ${ }^{*}$ & 0.614 \\
\hline I can't stop myself from doing something, even if I know it is wrong for me. ${ }^{*}$ & 0.638 \\
\hline I say inappropriate things. ${ }^{*}$ & 0.378 \\
\hline *Reversed item & \\
\hline
\end{tabular}




\section{NOTES}

